\title{
SOBRE UNA ANUNCIACIÓN DE HERNANDO DE ESTURMIO QUE SE CREÍA PERDIDA
}

\section{FERNANDO CRUZ ISIDORO UNIVERSIDAD DE SEVILLA}

RESUMEN: Identificamos una Anunciación que el pintor holandés Hernando de Esturmio (1515-1556) realizó en 1547 para el monasterio de dominicas de Madre de Dios de Sanlúcar de Barrameda (Cádiz), y que se consideraba en paradero desconocido por la historiografía especializada desde hace casi un siglo, cuando realmente nunca salió del edificio, pues se ha conservado en su clausura, en regular estado y como obra anónima.

PALABRAS CLAVE: Hernando de Esturmio, Pintura flamenca renacentista.

\section{A LOST ANUNNCIATION BY HERNANDO DE ESTURMIO}

SUMMARY: We identified the Annunciation made in 1547 by the painter dutch Hernando de Esturmio (1515-1556), for the Dominican monastery of Mother of God of Sanlúcar de Barrameda (Cadiz), that was considered by the historiography specialized in whereabouts unknown almost a century, when it really was in that same building, although in the convent cloister, in fair condition, and as anonymous work.

KEYWORDS: Hernando de Esturmio, Renaissance Flemish painting. 
A veces un autor considera perdida una obra de arte cuando no se encuentra en el lugar exacto para el que se realizó, sin llegar a interesarse suficientemente por localizar su paradero, aunque sólo se halle unos pocos metros más allá. Y el error se puede perpetuar si la historiografía posterior se limita a seguir esa publicación y no avanza en la investigación. Esa sucesión de descuidos es lo que ha mantenido, durante más de un siglo, que la Anunciación que el pintor holandés Hernando de Esturmio (1515-1556) realizó en 1547 para la primitiva iglesia del monasterio de dominicas de Madre de Dios de Sanlúcar de Barrameda (Cádiz) había desaparecido. Simplemente, los avatares del tiempo, y los gustos, hicieron que el retablo renacentista donde se ubicaba se desmontase a mediados del siglo XVIII, para erigir en su lugar el actual retablo mayor barroco. Y que los cuadros que lo configuraban, que ya no servían, se trasladaran a la clausura del monasterio. Con el paso del tiempo y su deterioro, se perdió la memoria del lugar que ocuparon y, como es habitual, paralelamente el nombre de su autor y su valía. Ese fue el destino del cuadro que estudiamos, porque la comunidad dejó que se perdieran las tablas laterales, y esta escena se montó, a la intemperie, en una hornacina del claustro mayor.

Repasemos lo publicado al respecto. Fragmentos de la documentación sobre este cuadro, y el retablo que lo albergaba, la divulgó el historiador Heliodoro Sancho Corbacho en $1931^{1}$, que se limitó a su transcripción, sin identificar su localización ni efectuar ningún análisis formal ni iconográfico. De forma paralela, Enrique Romero de Torres afirmará en su Catálogo monumental de España. Provincia de Cádir, de 1934, como "Este retablo fue vendido hace algunos años, según nos informaron". Como el subtítulo del catálogo lleva los años 1908 y 1909, señalaría un trabajo de campo anterior, con lo que parece darnos a entender que la noticia le fue dada en esos años, y dado el carácter conventual de la obra, no cabría pensar más que en la propia comunidad de dominicas. Recoge, además, las noticias básicas de la escritura de concierto, y la iconografía de la escena principal:

"En 1547 concertaron Hernando de Sturmes, pintor flamenco, y Francisco Ortega, entallador, con Marina Rodríguez, mujer de Cristóbal de Peñalosa, difunto, hacer un retablo para una capilla, en forma de arco, en la iglesia del convento de la Madre de Dios. La pintura que habría que llevar sería la Historia de la Encarnación de Nuestro Señor Jesucristo en el tablero principal (...)"'2.

\footnotetext{
${ }^{1}$ SANCHO CORBACHO, Heliodoro: Arte sevillano de los siglos XVI y XVII, Sevilla, 1931 (Documentos para la $\mathrm{H}^{\mathrm{a}}$ del Arte en Andalucía, III), pp. 12-13.

${ }^{2}$ ROMERO DE TORRES, Enrique: Catálogo monumental de España. Provincia de Cádiz.(1908-1909), vol. 1, texto, Madrid, 1934, p. 519.
} 
Esa afirmación rotunda llevaría a la historiografía posterior a mantener su pérdida o venta que, según esas publicaciones, tendría lugar a finales del siglo XIX o principios del XX. Sin embargo, se ha podido documentar en el archivo del monasterio que, aunque hubo un intento fallido de enajenación de pinturas en 1880, la obra no se encontraba en el lote de las inventariadas. En junio de ese año, el pintor sanluqueño Francisco de la Peña Almadana, apreció un conjunto de veinticinco cuadros en $1.950 \mathrm{pts}^{3}$. Tampoco se ha localizado en la documentación monacal la venta de ningún cuadro con esa iconografía en las tres décadas posteriores, con lo que esa afirmación parece poco válida.

Quizás la noticia fue fruto de un malentendido, al considerar el historiador que la venta de alguna de las piezas del retablo equivalía al conjunto, o simplemente fue una información tergiversada de un tercero. Y lo cierto es que ese bulo no beneficiaba en nada a las monjas, ya que una pérdida cualificada de su patrimonio, por venta o desidia, siempre resulta negativa de cara a la sociedad. Se ha comprobado históricamente cómo, a lo largo de los siglos, la comunidad sanluqueña ha intentado conservar y aumentar sus bienes, minimizando las enajenaciones a las que tuvieron que acudir en último extremo para hacer frente a sus necesidades.

La supuesta pérdida de todo el retablo, y de la escena central que nos ocupa, la mantuvo el profesor Juan Miguel Serrera en la monografía que dedicó a Esturmio en 1983. Incluirá la anotación documental en su apartado de "obras documentadas, perdidas o no identificadas”. Dirá: "En 1932 (sic), Romero de Torres informaba que la comunidad hacía pocos años que había vendido las tablas, cuyo paradero actual se desconoce"4. Y con ello, la noticia de su pérdida se ha perpetuado hasta la actualidad, pues esa monografía sigue siendo la base fundamental de cualquier nueva aportación sobre Esturmio ${ }^{5}$.

Sin embargo, la obra simplemente se encontraba en otro lugar del edificio. Y para que no quede duda en la identificación, analicemos brevemente la documentación publicada. Sancho Corbacho recoge cómo la señora Marina Rodríguez concertó en Sevilla, el 12 de abril de 1547, su ensambladura de madera con el entallador Francisco de Ortega. Era vecino de la collación de Santa María, y la escritura pasó ante el escribano Andrés de Oviedo ${ }^{6}$. La pintura la tomó "Fernando desturmes, pintor flamenco, vesino que soy desta çibdad de Sevilla en la

\footnotetext{
3 CRUZ ISIDORO, Fernando: El monasterio de Madre de Dios. Historia y Patrimonio artístico de las dominicas sanluqueñas, Sanlúcar de Barrameda, Monasterio de la Anunciación del Señor (vulgo de Madre de Dios), 2018, pp. 191-192, 598, 600.

4 SERRERA, Juan Miguel: Hernando de Esturmio. Sevilla, Diputación, 1983, p. 100.

${ }^{5}$ Como en VALDIVIESO, Enrique: Historia de la pintura sevillana. Siglos XIII al XX, Sevilla, Guadalquivir, 1986, pp. $74-77$.

${ }^{6}$ La localizó en el Archivo Histórico Provincial de Sevilla, secc. Protocolos Notariales, Oficio XVII, libro I, fol. 995 vto.
} 
collación de San Andrés". Ambos se comprometieron a "fazer un retablo para una capilla que vos tenéis en la villa de Sanlúcar de Barrameda, en la yglesia e monasterio de nuestra señora la Madre de Dios".

Por el tenor y la cronología, se desprende que era para una capilla de la primitiva iglesia gótico-mudéjar del monasterio. Podría tratarse de la mayor o presbiteral, aunque cabría la posibilidad de que fuese una colateral de carácter funerario. La nave y los dos coros del templo actual los realizó, entre 1574 y 1576, el ingeniero militar napolitano Juan Pedro Livadote, que estuvo temporalmente al servicio de la condesa de Niebla $\mathrm{D}^{\mathrm{a}}$ Leonor Manrique de Sotomayor y Zúñiga, viuda del conde de Niebla D. Juan Claros de Guzmán. Esa enérgica señora desarrolló un activo patronazgo artístico en la capital de su estado señorial, y en otros lugares de éste, durante los años que ejerció como curadora en la minoría de edad de su hijo D. Alonso, VII duque de Medina Sidonia ${ }^{7}$.

Por su parte D. a Marina, entonces avecindada en el barrio sevillano de San Bartolomé, era la viuda de Cristóbal de Peñalosa, un personaje de cierta importancia en la sociedad sanluqueña, integrante de la pequeña corte ducal, que había sido alguacil mayor de la villa en 1536, regidor del cabildo municipal desde enero de 1539, y tesorero del citado conde D. Juan Claros desde $1542^{8}$. Según las condiciones, el retablo se confeccionaría en sólo cuatro meses, pues para finales de agosto debía estar, "todo fecho y acabado de buena obra" a vista de oficiales. Se contrató el ensamblaje y el entalle por 12.000 maravedíes, y la pintura y el dorado por 50 ducados. Tendría una altura de doce palmos y medio y una anchura de ocho, o sea, 2,5 por 1,67 metros aproximadamente, en madera de castaño y nogal " $y$ de teja sana e seca e tal qual conbenga a buena obra”.

Su forma sólo podemos intuirla, pero dispondría de banco, pues allí Esturmio debía pintar al centro una tarja con "un letrero dixiendo en él lo que nos fuere mandado y que las letras sean fechas de oro". Indudablemente la dedicatoria de la persona que encargaba el retablo. Y, a ambos lados, pintaría otras dos tablas con los retratos de la pareja donante y sus hijos organizados por sexos. En una el padre con cuatro varones, y en la otra la madre con las cuatro hijas.

Ese retrato colectivo resulta interesante, pues se convierte en un antecedente del banco del retablo de la Purificación de la Catedral hispalense, que el bruselés Pedro de Campaña pintó

\footnotetext{
${ }^{7}$ CRUZ ISIDORO, Fernando: "Juan Pedro Livadote al servicio de la condesa de Niebla: el convento de Madre de Dios (1574-1576)", Laboratorio de Arte, 22, 2010, pp. 67-75.

${ }^{8}$ VELÁZQUEZ GAZTELU, Juan Pedro: Catálogo de todas las personas ilustres y notables de esta ciudad de Sanlúcar de Barrameda. Desde la mayor antigüedad que se ha podido encontrar en lo escrito hasta este año de 1760, edic. literaria y transcrip. de F. Cruz Isidoro, Sanlúcar de Barrameda, ASEHA, 1996, p. 391.
} 
en 1555 para la capilla del Mariscal D. Diego Caballero. Dispuso de igual forma diferenciada por sexos, los retratos del caballero con su hermano y su hijo, y de su esposa D. ${ }^{a}$ Leonor de Cabrera, su hermana, otra señora joven y sus dos hijas. Práctica que también se siguió en el del clérigo D. Pedro Santiago, y diversos familiares, del banco del retablo recompuesto de la Virgen de la Paz de la parroquia sevillana de San Pedro, fechado hacia 1560, obra de Pedro de Campaña "el Mozo", hijo del afamado pintor de igual nombre?.

Nos interesa cómo la escena principal que Esturmio se obligó a pintar fue "la ystoria de la encarnaçión de nuestro señor ihesuxpo, cunplidamente conforme a buena obra, y esto vaya en el tablero prenzipal". Representa la advocación del monasterio y por tanto debía ubicarse en la calle central, lo que nos lleva a pensar que se utilizaría como retablo mayor. De todo el conjunto, es ésta la única pieza que identificamos en el interior del edificio, pues del resto nada sabemos.

A ambos lados "del guardapolvo" se pintarían dos escenas como alas o entrecalles, con devociones particulares de la donante, formando sacras conversaciones. Una pareja sería la formada por el fraile agustino San Nicolás de Tolentino, predicador y taumaturgo de gran devoción popular frente a la peste y la fiebre, patrón de los agonizantes y de las almas del purgatorio, y el franciscano San Antonio de Padua, al que se invocaba en los naufragios por los marinos portugueses, y como abogado de los prisioneros. La otra un San Sebastián, patrono contra la peste, y un San Cristóbal, que lo era del difunto esposo de D. ${ }^{a}$ Marina, y en la época, un reputado protector contra la muerte súbita sin confesión, pues bastaba mirarlo para quedar protegido todo un día de esa desgracia.

El retablo culminaba en forma de arco o frontón curvo, conforme a una medida que les dio el hijo de D. ${ }^{a}$ Marina. Debía "llevar por enzima su guardapolbo", que descendería "por los lados", rematando "con su corona por el arco fecha de talla". El marco y el entalle lo dorarían con oro fino ${ }^{10}$.

Sobre la traza del retablo, de transición renacentista con resabios goticistas, podemos hacernos idea por los enmarques utilizados para el retablo mayor de la iglesia de San Pedro de Arcos de la Frontera, coetáneo del que estudiamos, que realizaron Pedro Fernández de Guadalupe, Antón Sánchez de Guadalupe y el propio Esturmio entre 1538 y $1547^{11}$. Y con

\footnotetext{
9 VALDIVIESO, Enrique: Historia de la pintura sevillana...op. cit., pp. 68-69; Pedro de Campaña, Sevilla, Endesa, 2008, pp. 102-105, 188.

${ }^{10}$ SANCHO CORBACHO, Heliodoro: Arte sevillano de los siglos XVI y XVII...op. cit, pp. 12-13. SERRERA, Juan Miguel: Hernando de Sturmio...op. cit., p. 100.

11 Se relacionan con Esturmio la Piedad, entierro de Cristo, la Resurrección, conversión y martirio de San Pablo, la Epifanía, presentación en el Templo, Bautismo de Cristo y la Asunción. ALONSO DE LA SIERRA, Lorenzo, ALONSO DE LA SIERRA, Juan, POMAR RODIL, Pablo y MARISCAL, Miguel Ángel: Guía artística de Cádiz. y su provincia (II), Sevilla, Diputación / Fundación José Manuel Lara, 2005, pp. 314-317.
} 
respecto a la estructura de guardapolvo en forma de arco, sería similar al usado en su Alegoría de la Inmaculada Concepción del panteón de los condes de Ureña de la Colegiata de Osuna, de 1555.

En cuanto a Esturmio, baste recordar cómo su conocimiento como pintor holandés venía de antiguo, desde que Ceán Bermúdez le dedicase un apartado en su Diccionario histórico en 1800. Recoge su procedencia y labor en la escuela pictórica sevillana de mediados del siglo XVI, y su obra esencial, la del altar de los Evangelistas de la Catedral hispalense, fechada en 1555 y firmada Hernandus Sturmius Ziriczensis. Nuevas noticias documentales se fueron publicando en los años posteriores, como las de José Gestoso en 1900 en su Ensayo de un Diccionario $^{12}$. No obstante, su personalidad artística no quedaría perfilada hasta que el historiador alemán August L. Mayer le dedicase, en 1911, un apartado en su monografía sobre la escuela pictórica sevillana, que marcó un hito en la investigación, pues fue la primera publicación dedicada a una escuela pictórica española. Recogerá todas las noticias publicadas hasta ese momento, dando forma básica a su biografía y catálogo esencial, su entorno laboral y de amistades, patronos y estilo personal ${ }^{13}$, con una valoración estética que se mantuvo durante décadas. Diego Angulo lo encuadra como pintor rafaelista, que gozó en Sevilla de cierta reputación y gran volumen de trabajo, con importantes retablos y mecenas de prestigio, como los duques de Osuna y los canónigos de la catedral, "sin que sus méritos artísticos lo justifiquen demasiado", por "su estilo seco, nervioso, violento". De amaneramiento exagerado, lo considera heredero de los holandeses Scorel y Heemskerk, de los que toma "su afición a los efectos de clarooscuro y a esas actitudes en que los personajes se retuercen como las raíces de un olivo milenario, y las manos se crispan como presas de pasmo”. Recoge el catálogo documentado desde décadas atrás, haciendo notar que sus obras son ejecutadas con prisa y excesiva colaboración de oficiales ${ }^{14}$. Estimación y catálogo, mantenidos por José Camón y otras publicaciones generales ${ }^{15}$, hasta que el profesor Serrera Contreras le dedicó la citada monografía en 1983, siendo los aportes posteriores de carácter puntual.

Nacido hacia 1515 en la localidad holandesa de Zierikzee, se desconoce en buena medida su formación, aunque se constata en sus composiciones el empleo reiterado de

12 CEÁN BERMÚDEZ, Juan Agustín: Diccionario histórico de los más ilustres profesores de las Bellas Artes de España, prólogo de M. Morán Turina, Madrid, Akal, 2001, pp. 395-396. GESTOSO Y PÉREZ, José: Ensayo de un diccionario de los artífices que florecieron en Sevilla desde el siglo XIII al XVIII inclusive, t. II, P-Y, Sevilla, 1900, pp. 19-20. ${ }^{13}$ MAYER, August Liebmann: La escuela sevillana de pintura, presentación y edición de Daniel Romero, Sevilla, Cajasol, 2010, pp. 73-78; La pintura española, 1926, $4^{\circ}$ ed., Barcelona, Labor, 1947, p. 107.

14 ANGULO INIÍGUEZ, Diego: Pintura del renacimiento (Ars Hispaniae, vol. XII), Madrid, Plus-Ultra, 1954, pp. 210-211.

${ }_{15}$ CAMÓN AZNAR, José: La pintura española del siglo XVI, (Summa Artis, vol. XXIV), Madrid, Espasa-Calpe, 1970, pp. 389-390. CHECA, Fernando: Pintura y escultura del renacimiento en España, 1450-1600, Madrid, Cátedra, 1999 , pp. 243-244. 
grabados flamencos, alemanes y miguelangelescos, que hizo pensar al profesor Valdivieso cierta relación con Egbert van Heemskerck por el uso común de estampas. Más recientemente, Gómez Sánchez, considera la posibilidad de que fuese discípulo del liejense Lambert Lombard (ca.1505-1566) ${ }^{16}$, lo que confirma Romero Dorado respecto a sus tipos humanos, paleta y concreción de vestiduras, asimiladas en la etapa de oficial en su taller ${ }^{17}$. También es factible una probable estancia en Italia, por su marcado estilo ecléctico, entre los renacimientos flamenco e italiano, similar al expuesto por Campaña, del que parece deudor. Trabajó en Sevilla entre 1537, fecha a partir de la que se conocen datos de su biografía y producción, y 1556, en la que fallece. Desarrolla un estilo un tanto seco y agrio a la hora de interpretar las anatomías humanas, que suelen ser de canon manierista alargado, a veces con contrastes entre los personajes de los diferentes planos. Resulta desigual en cuanto a la representación espacial, pero evidencia maestría y elegancia a la hora de componer gestos y actitudes, y virtuosismo en el plegado de las vestiduras, de rica gama cromática en matices ${ }^{18}$.

En cuanto a la técnica, toda su producción conocida hasta el momento está pintada al óleo sobre tabla, con paneles formados por cuatro o cinco tableros, de madera de borne seca, ensamblados con lengüetas de ese material, pegando las juntas con engrudo de Flandes. La superficie se enlucía con cola y luego aplicaba la preparación, consistente en un lienzo sobre el que disponía una primera capa gruesa de yeso vivo, generalmente molido con cola, y una segunda y tercera más finas, de yeso apagado, tras lo que dibujaría y usaría los colores elegidos, barnizando finalmente. El uso de ese material ha provocado que con los años sus tableros muestren un evidente deterioro, alabeados y con pérdidas de materia pictórica, sobre todo en las uniones ${ }^{19}$.

La obra que tratamos se insertaría en su segunda etapa, desarrollada entre 1545 y 1550, según la evolución advertida en su producción y estilo por el profesor Serrera Contreras. En la Anunciación sanluqueña, utiliza grabados de Durero en la configuración espacial y el agrupamiento de personajes y gestos, tomados de la serie de la Vida de la Virgen María (1500-

\footnotetext{
16 GÓMEZ SÁNCHEZ, Juan Antonio: "Hernando de Esturmio. Un pintor neerlandés en la Sevilla del renacimiento", en El San Roque del Convento de Santa Clara: una obra maestra de Esturmio restaurada, coord. por Benito Navarrete Prieto, y dirección técnica de Gabriel Ferreras Romero y Rocío Magdaleno Granja, Sevilla, Ayuntamiento, 2015, pp. 15-67.

${ }^{17}$ ROMERO DORADO, Antonio: "Una nueva obra de Hernando de Sturmio. La Virgen de la Antigua de Medina del Campo", BRAC, 51, 2016, pp. 44-45.

18 SERRERA, Juan Miguel: "Pinturas y pintores del siglo XVI en la catedral de Sevilla", en La Catedral de Sevilla, Sevilla, Guadalquivir, 1990, $2^{\text {a }}$ ed., 1991, pp. 390-391. VALDIVIESO, Enrique: Historia de la pintura sevillana...op. cit., pp. 74-77. ÁVILA Ana y otros, El siglo del renacimiento (Historia del Arte Español), Madrid, Akal, pp. 226227.

${ }^{19}$ SERRERA, Juan Miguel: Hernando de Esturmio...op. cit., pp. 57-58.
} 
1504) (fig. 1) y de la Pequeña Pasión (1511) ${ }^{20}$ (fig. 2), con su típica representación mariana de cuello de base ancha y desarrollo alargado.

\section{Figuras 1 y 2}

\section{Anunciación (ca. 1503) y (ca. 1510)}
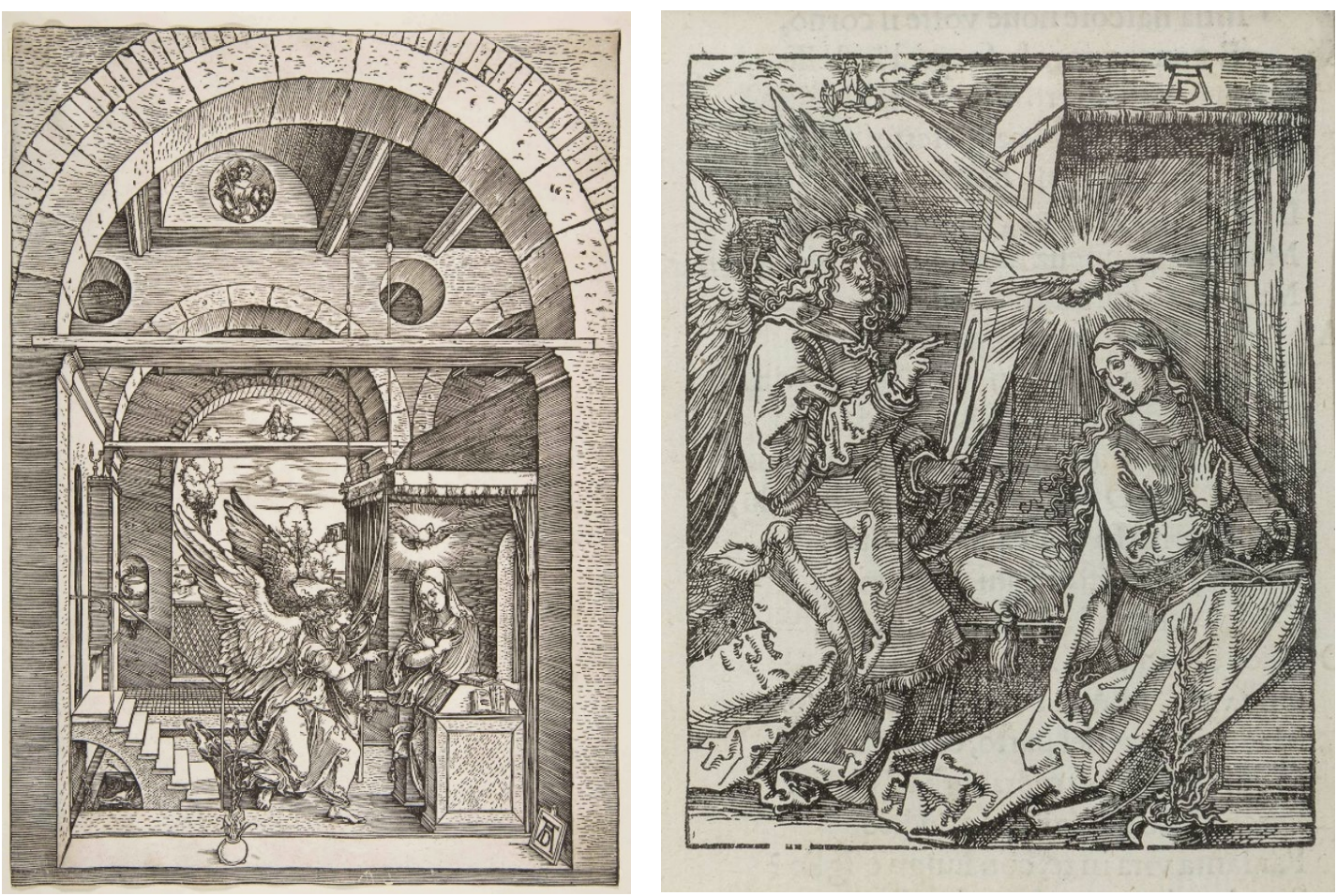

Alberto Durero. Libre uso

Se trata de una escena de interior muy íntima, que se desarrolla en la penumbra del cuarto de María, sentada ante un bufete, absorta en una lectura piadosa y con el símbolo parlante de su virginidad, la jarra de azucenas. Ese recogimiento se ve alterado por la súbita presencia del arcángel San Gabriel, que entra arrebatadoramente por la izquierda, pisando fuerte con sus pies desnudos y con el cetro que le avala, como mensajero de Dios, para anunciarle la buena nueva. Lo comprobamos por el gesto de su dedo índice señalando hacia el cielo, produciéndose la Encarnación del Verbo por la gracia del Espíritu Santo, representado como Paloma Blanca que desciende hasta la Virgen, inserta en una aureola dorada, y por la pequeña estrella que gravita sobre la cabeza de María. La larga cabellera rubia ensortijada del ser angelical queda sujeta con una diadema a la frente, enriquecida con un broche, destacando la fimbria de su manto, dotada de inscripción.

${ }^{20}$ LE INCISIONI DI ALBRECHT DÜRER. Introduzione, schedule e didascalie di Marco Antonio Michiel, Franco Martella editore, s.l., s.f., pp. 241, 258 
Dios Padre, representado de medio cuerpo, asiste complacido al acto de sumisión en el vértice del triángulo que forma la escena y la pirámide visual, aprovechando el remate curvo, envuelto en un ampuloso manto rojo y en un súbito rompimiento de Gloria. Su inspiración es similar a la representación sorpresiva que para este personaje adopta Lambert Lombard en su Adoración de los pastores del convento de las concepcionistas de San Juan de la Palma de Sevilla, actualmente en el Museo de Bellas Artes de la ciudad, de hacia $1550^{21}$. Gesticulante, la Dextera Domini adopta la postura de bendecir el acto. La perspectiva de la escena se apoya en la representación del pavimento, mal retocado hace unos años, de enlosado blanco y negro. Y en una centrada apertura espacial, que abre a un fondo de paisaje con una colina abombada, que se atisba entre los balaustres del antepecho de una ventana, de rodapiés moldurado.

Completa la escenografía la ubicación al fondo del flanco derecho de un lecho sobre un pequeño estrado, con dos almohadas y dosel. Y el imprescindible jarrón, aquí metálico y panzudo por los destellos, con decoración de entrelazo o meandro y de dos asas, con las azucenas virginales, dos abiertas y cinco capullos. La lectura iconográfica se apoya en dos inscripciones: $A V E$ GRACIA PLENA, girando en torno al cetro, y ECE AGELLA D(omi)NI sobre el lecho. (Fig. 3)

Ratifica que esta obra es la de Esturmio, que la composición, tipología, postura y gestos de los personajes, así como los objetos de bodegón, resultan idénticos a la pequeña Anunciación que el pintor contrató dos meses más tarde, en junio de 1547, con el escultor de imaginería Nicolás de León, para el banco del retablo de la capilla del Colegio-Universidad de Osuna. Formaba parte de un lote de siete tablas por 30 ducados, que encargó el IV conde de Ureña D. Juan Tellez-Girón ${ }^{22}$. (Figs. 4, 5, 6 y 7)

La similitud de fechas señala el uso paralelo de unos mismos modelos o grabados, siendo difícil calibrar qué obra sirvió de referente a la otra, aunque el pequeño formato de la de Osuna podría hacer pensar en un boceto de idea previa, aunque fuese de contratación posterior.

Para cerrar esta exposición, señalar cómo Esturmio mantuvo relación profesional con Sanlúcar y la Casa ducal de Medina Sidonia. Se conserva otra obra suya en la capilla de Ánimas de la Iglesia Mayor de Ntra. Sra. de la O, el tríptico de la Sagrada estirpe de la Virgen, que ya incluyó en su libro Gestoso en 1900. La concertó con el alcalde sanluqueño Alonso de Castro dos años más tarde, en enero de 1549, y fue tasada en julio, en 10 ducados, por

21 IZQUIERDO Rocío y MUÑOZ, Valme: Museo de Bellas Artes. Inventario de pinturas, Sevilla, 1990, p. 27. VALDIVIESO, Enrique: Museo de Bellas Artes de Sevilla. Pintura, T. II, Sevilla, Gever, 1991, pp. 84-85.

${ }^{22}$ MAYER, August Liebmann: La escuela sevillana de pintura ...op. cit., p. 75. SERRERA, Juan Miguel: Hernando de Esturmio...op.cit., pp. 22, 100. 
Juan de Zamora y Pedro de Campaña, con quien colaboraría posteriormente para la Casa ducal $^{23}$. A tenor de los tipos, estilo y composición, podrían vincularse con su producción las pinturas murales de la capilla mudéjar del testero de la nave de la epístola de esa parroquia, que sirve de tránsito a la sacristía, por el fragmento que se conserva en la esquina izquierda del muro ${ }^{24}$.

Figura 3

Hernando de Esturmio. Anunciación. Claustro del monasterio de Madre de Dios de Sanlúcar de Barrameda (Cádiz)

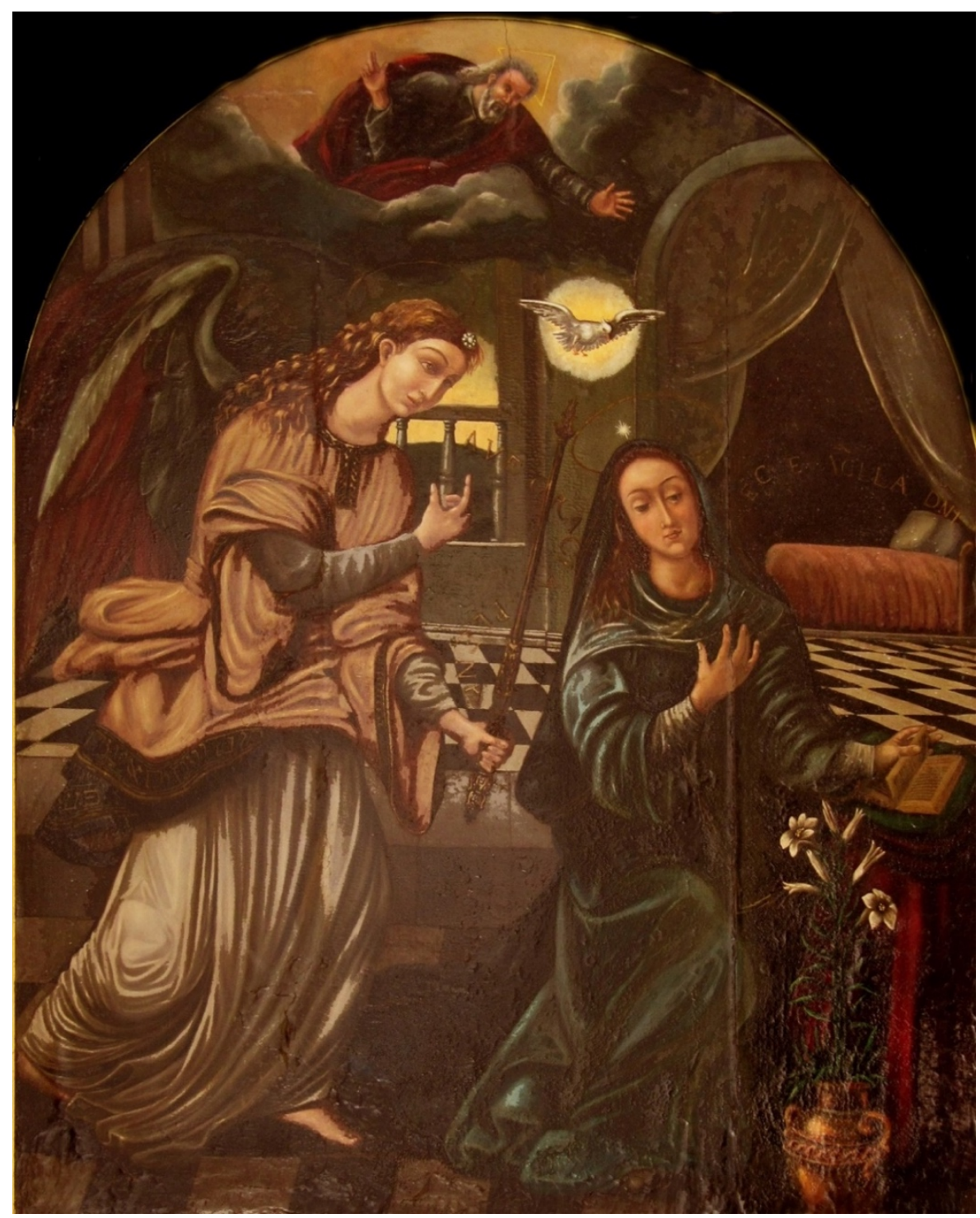

Fotografía del autor

23 GESTOSO Y PÉREZ, José: Ensayo de un diccionario de los artifices...op. cit., pp. 19-20. SERRERA CONTRERAS, Juan Miguel: Hernando de Esturmio...op. cit., p. 92. CRUZ ISIDORO, Fernando: "Arte y arquitectura en la Sanlúcar del siglo XVI", en ed. lit. de F. Cruz Isidoro Sanlúcar la Puerta de América, Sanlúcar de Barrameda, Fundación Puerta de América, 2012, pp. 287-288.

${ }^{24}$ CRUZ ISIDORO, Fernando: “Arte y arquitectura en la Sanlúcar del siglo XVI” ... op. cit., pp. 287-288. 


\section{Figura 4}

Hernando de Esturmio. Anunciación de la Colegiata de Osuna

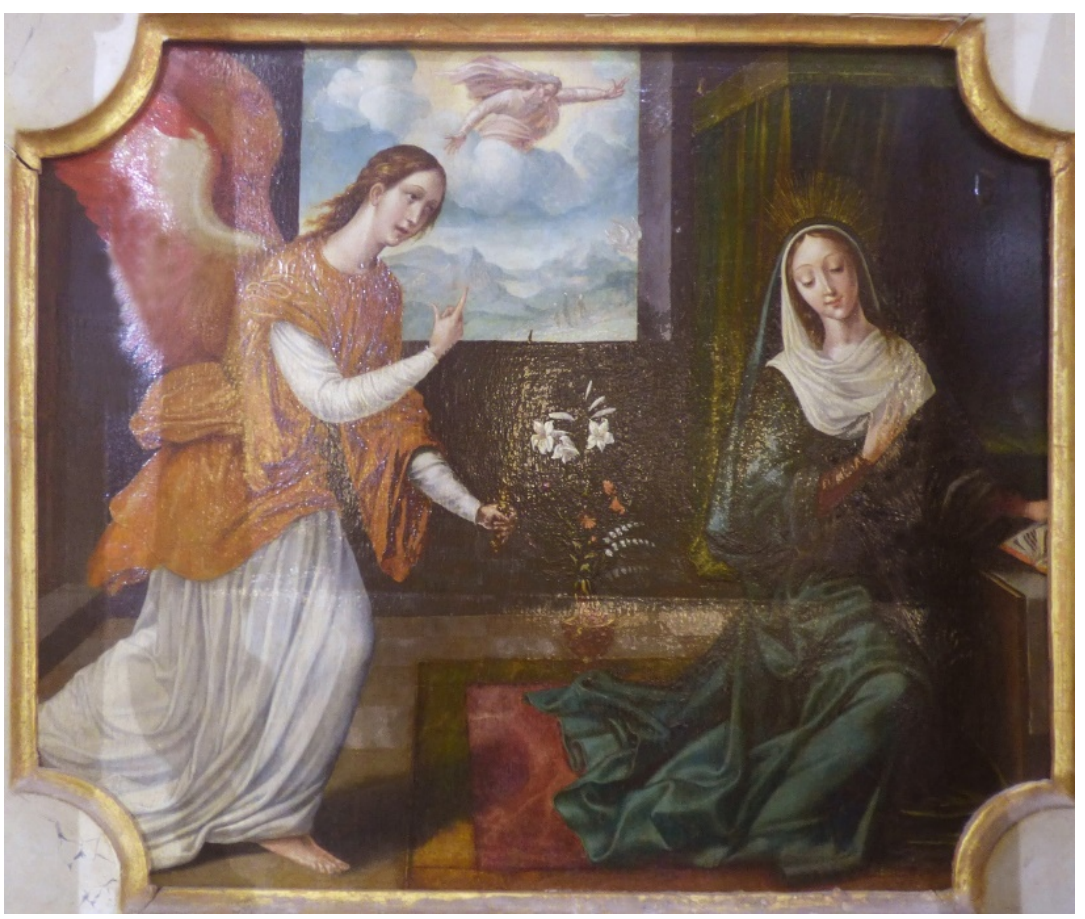

Fotografía de Ana Cabello Ruda

Figura 5

Hernando de Esturmio. Anunciación del convento sanluqueño y de la Colegiata de Osuna
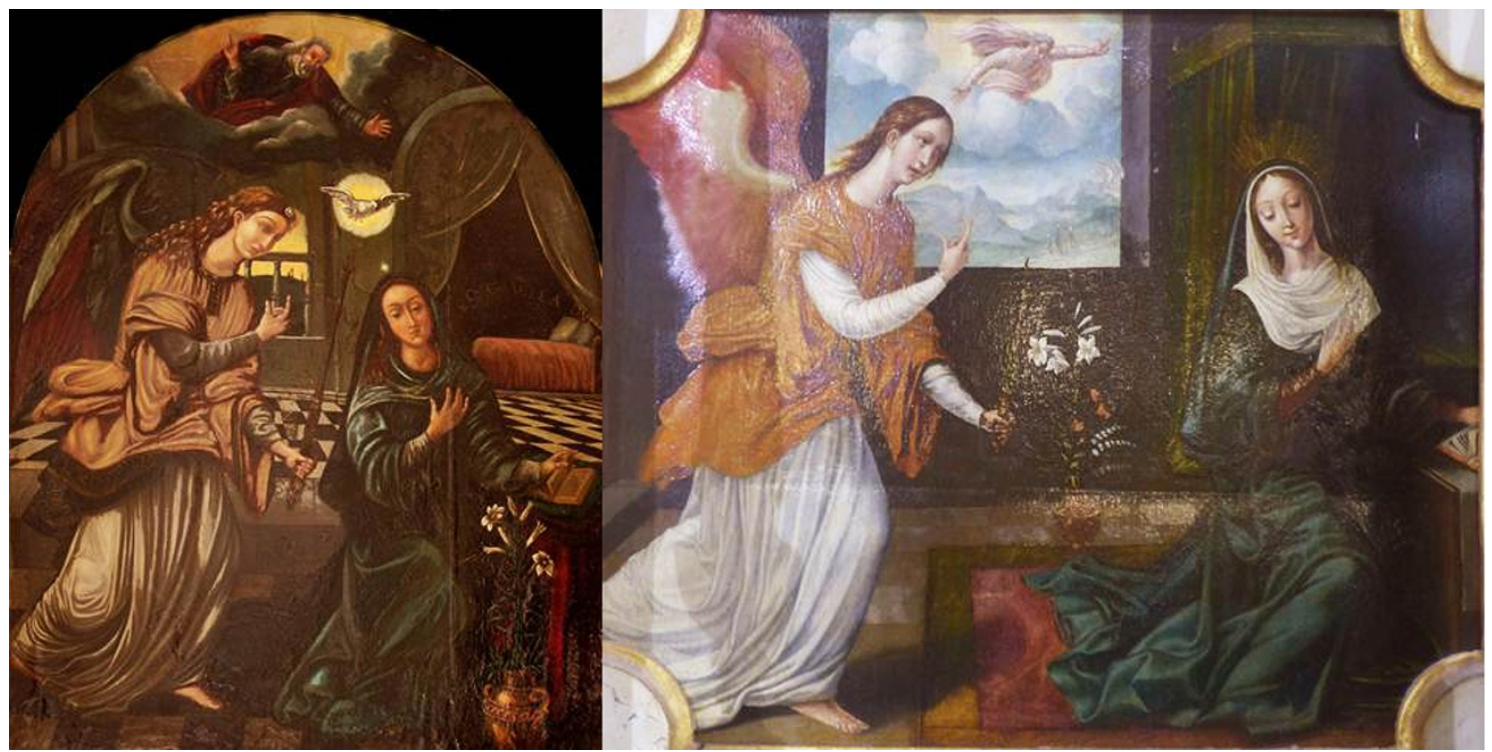

Fotografías del autor y de Ana Cabello Ruda 
Figura 6

Detalle de la Virgen María de las Anunciaciones de Sanlúcar de Barrameda y

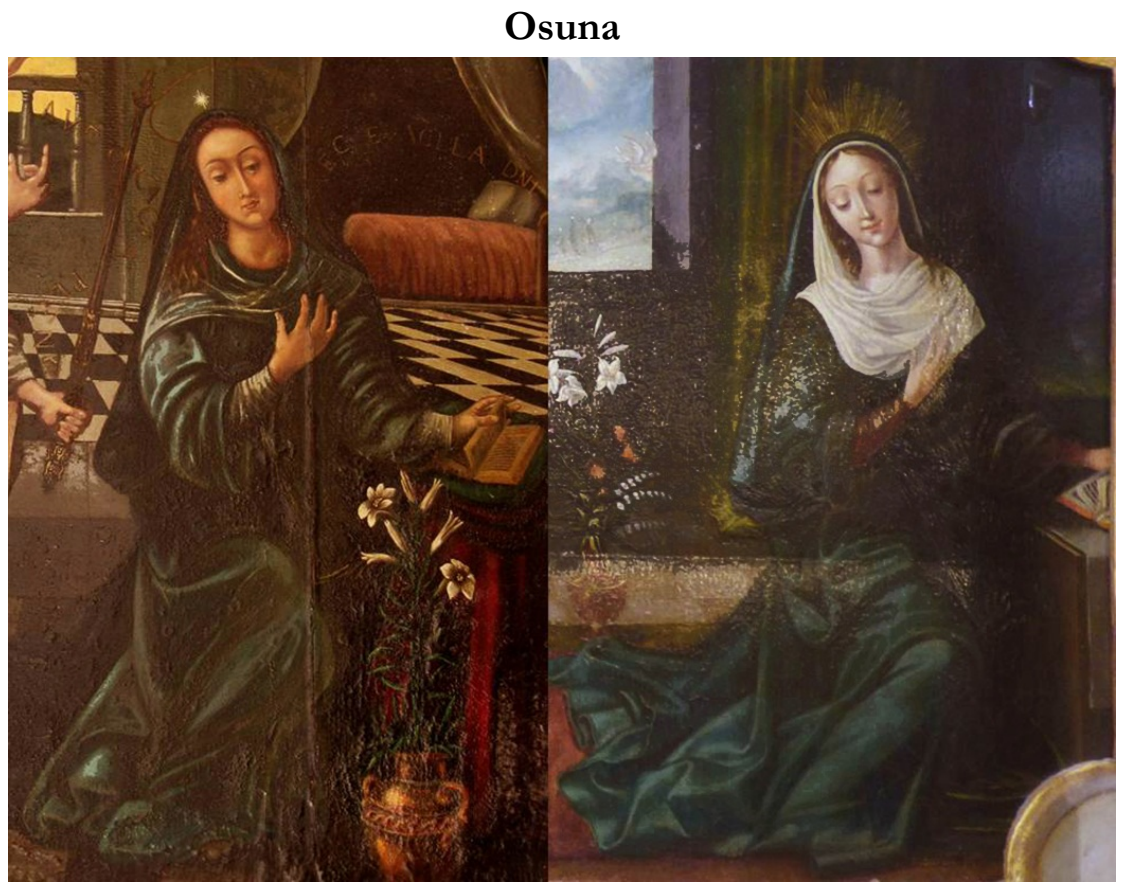

Fotografías del autor y de Ana Cabello Ruda

Figura 7

Detalle del arcángel san Gabriel de las Anunciaciones de Sanlúcar de Barrameda y

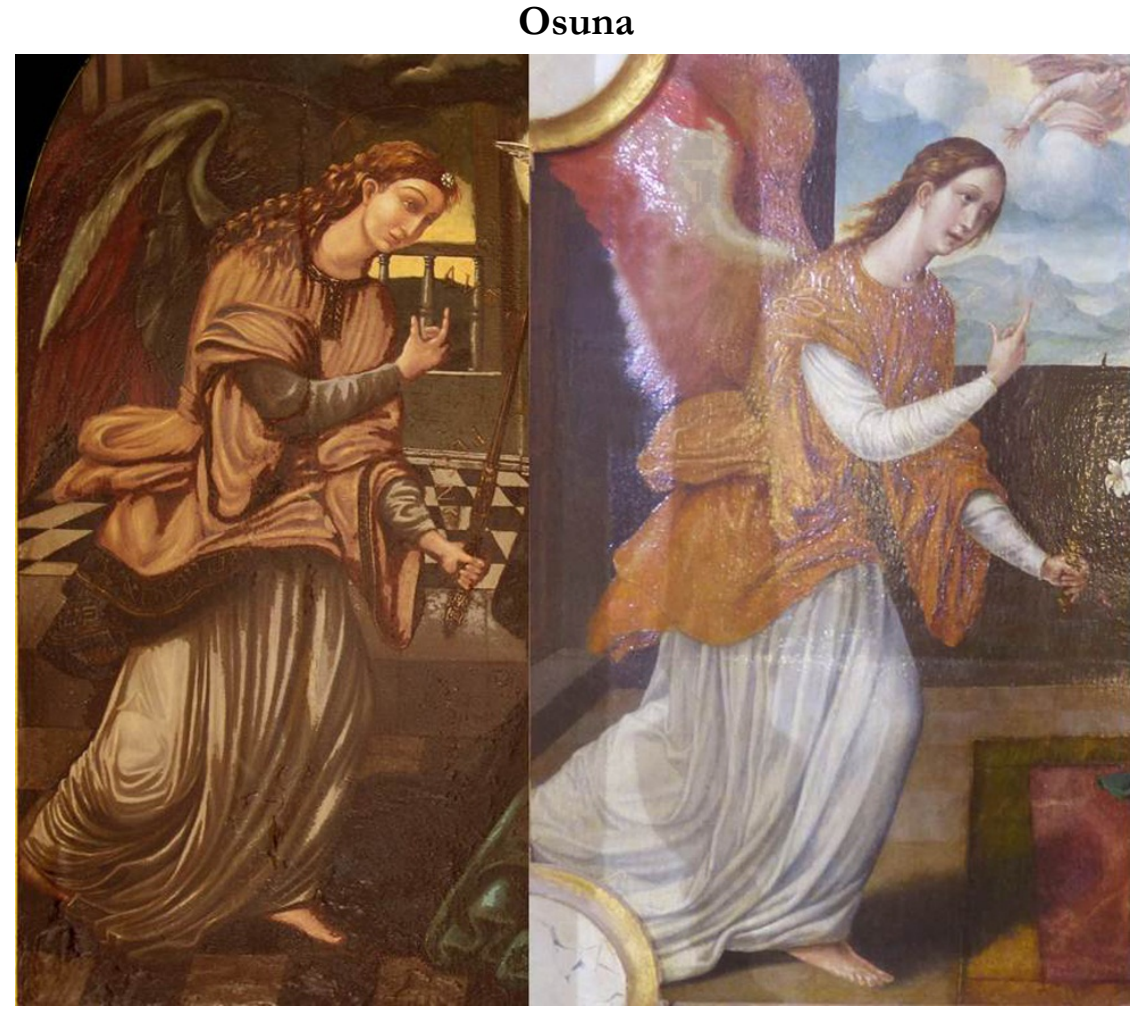

Fotografías del autor y de Ana Cabello Ruda 
Casi una década más tarde, al final de su etapa magistral, tras realizar entre 1553 y 1555 sus obras más afamadas, el retablo de Santa Catalina de la parroquia sevillana de Santa Ana, en Triana, y el de los Evangelistas de la Catedral hispalense, volverá a la localidad en 1556 de la mano de Campaña. A requerimiento de la condesa de Niebla $\mathrm{D}^{\mathrm{a}}$ Leonor Manrique de Sotomayor, concertaron el programa pictórico funerario de la primitiva iglesia del convento de Santo Domingo de Guzmán, espacio que hoy forma parte de la "sacristía" de la bodega "Herederos de Argüeso". Ambos se desplazaron para tomar medidas, pagándoles la condesa para el viaje 2 ducados a cada uno el 30 de marzo. Esturmio contrató los dos cuadros colaterales en 33 ducados, pero su fallecimiento en noviembre determinó a Campaña dejarlos en manos del pintor Luis Hernández. No se han localizado ${ }^{25}$.

En cuanto a los avatares sufridos por la Anunciación del monasterio de las dominicas, hasta su actual ubicación, creemos que tras la reconstrucción del templo por la condesa $\mathrm{D}^{\mathrm{a}}$ Leonor, el retablo fue repuesto en su presbiterio provisional, aproximadamente a la altura donde ahora se ubica el retablo de Santa Catalina de Siena, ya que la actual capilla mayor, más profunda, no se hizo hasta 1605. Posiblemente fue adaptado para darle empaque, como demuestra la libranza ducal de 44 reales, de 6 de septiembre de 1576, para el entalle de la guarnición del banco del retablo mayor, al carpintero flamenco y vecino de Sevilla Alberto Van Besel, de personalidad artística desconocida ${ }^{26}$.

Finalmente, cuando se hizo el actual retablo mayor a mediados del siglo XVIII ${ }^{27}$, las pinturas de Esturmio fueron desplazadas a otros espacios, hasta quedar sólo la principal, relegada a una hornacina en un ángulo del claustro. (Fig. 8)

Al permanecer durante décadas a la intemperie, su estado de conservación se degradó, lo que determinó a la comunidad, hace unos años, para evitar su pérdida y por incapacidad económica para acudir a un restaurador, encargar su remozamiento a Luis Florencio Muñagorri, un artesano de la localidad ${ }^{28}$. Con anterioridad ya había trabajado para las dominicas como decorador, con el ornato pictórico del frontón del comulgatorio y de la bóveda de la escala o escalera principal, entre otras intervenciones. Pero las que resultan

\footnotetext{
25 Sólo se ha identificado la Piedad de Campaña, ahora en el museo de BBAA de Cádiz. SERRERA CONTRERAS, Juan Miguel: "Pedro de Campaña y la Casa de Medina Sidonia (A propósito de la "Piedad" del Museo de Bellas Artes de Cádiz)", Archivo Hispalense no 251, 1999, pp. 245-249, 255-261. VALDIVIESO, Enrique: Pedro de Campaña, Sevilla, Fundación Sevillana Endesa, 2008, pp. 136-138. CRUZ ISIDORO, Fernando: "El Convento de Santo Domingo de Sanlúcar de Barrameda: patronazgo de los Guzmanes, proceso constructivo y patrimonio artístico (1528-1605)", Laboratorio de Arte, 23, 2011, pp. 84-87; "Arte y arquitectura en la Sanlúcar del siglo XVI" ... op. cit., pp. 251-253.

${ }^{26}$ Sobre el retablo se colocó un crucificado. AFCMS: Archivo Fundación Casa Medina Sidonia leg. 2.633, s/f.

${ }^{27}$ CRUZ ISIDORO, Fernando: El monasterio de Madre de Dios...op. cit., pp. 327-356.

${ }^{28}$ Noticia facilitada por la madre priora y cronista María Teresa Martín Cabrera.
} 
poco apropiadas son sus intrusiones en materia de restauración, como en la burda policromía del crucificado renacentista de la Paz y en el repinte del lienzo de la Última Cena del refectorio, una obra barroca que atribuimos al pintor Francisco Juanete. En el embaldosado de ese cuadro se puede leer: "Restaurado por Luis Florencio / Muñagorri Año 1987”. Esa inscripción nos sirve de testimonio documental de su actividad sobre el patrimonio artístico del monasterio, pues del resto sólo contamos con testimonios orales de la comunidad. Y, del análisis del cuadro, su inadecuado método de trabajo, que en nada sigue las prescripciones básicas de la aceptada carta del restauro. Esencialmente consiste en perfilar los personajes de la composición para su más fácil visión, lo que entraña endurecer su fisonomía, creando contornos nerviosos de formas básicas. Y luego refresca los colores y tapa lagunas con tonos básicos y duros, que al final extiende a todo el entorno, haciendo desaparecer las matizaciones de la paleta original con un repinte general ${ }^{29}$. Con ello entorpece y hace casi imposible la lectura de la composición creada por el autor de la obra.

Figura 8

La Anunciación de Esturmio en su actual ubicación, en una hornacina del claustro.

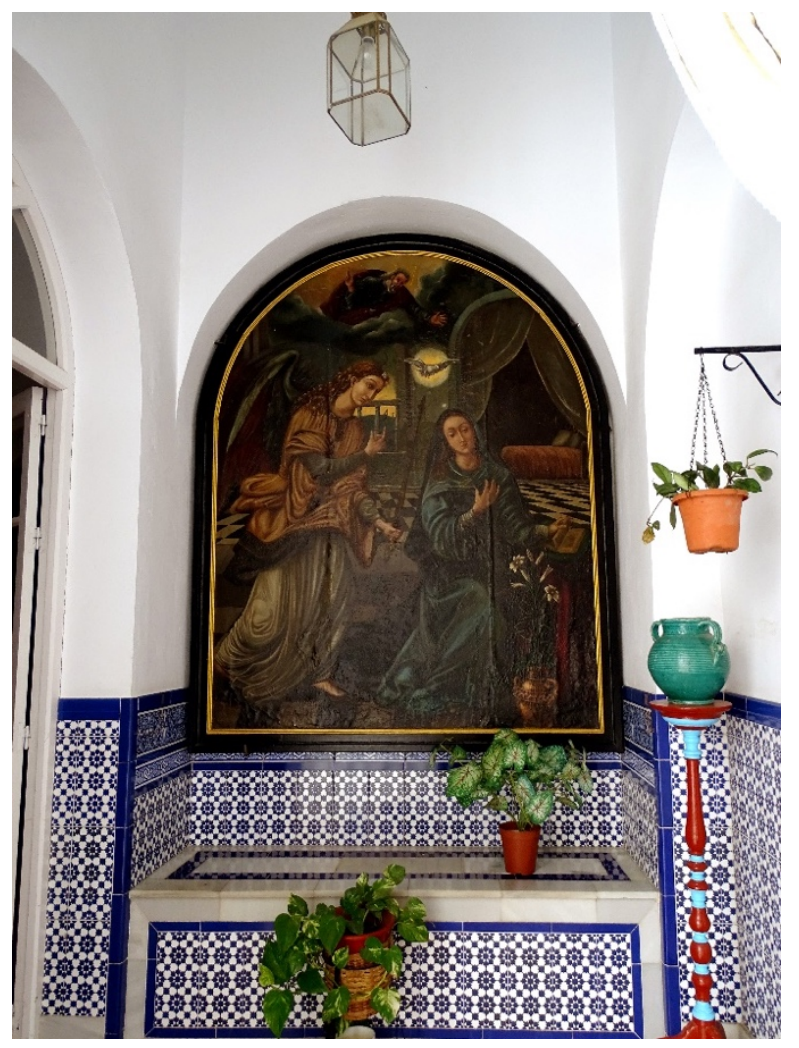

Fotografía del autor

${ }^{29}$ CRUZ ISIDORO, Fernando: El monasterio de Madre de Dios...op. cit., pp. 391, 395, 547, 558. 
En la Anunciación de Esturmio se siguen idénticas directrices. Perfiló duramente los contornos de los personajes y objetos, y completó lagunas que se evidencian con la luz rasante, siendo los repintes claros a simple vista. De nuevo se distorsiona la percepción, quedando únicamente a salvo la composición general y los tipos humanos.

Además, la obra presenta problemas estructurales, como en las uniones del soporte lignario, que provocan embolsamientos del lienzo, roturas y desprendimientos pictóricos. Pero, aun así, el cuadro se ha preservado y mantiene parte del noble aspecto original que le infundiera Esturmio, y que todavía se podría recuperar con una verdadera restauración, lo que, sin duda, redundaría en el aumento del excelso patrimonio artístico gaditano. 